\title{
Theory of mind development and executive functioning in elementary school children
}

\author{
Dana Lee Futoran \\ West Virginia University
}

Follow this and additional works at: https://researchrepository.wvu.edu/etd

\section{Recommended Citation}

Futoran, Dana Lee, "Theory of mind development and executive functioning in elementary school children" (1999). Graduate Theses, Dissertations, and Problem Reports. 710.

https://researchrepository.wvu.edu/etd/710

This Thesis is protected by copyright and/or related rights. It has been brought to you by the The Research Repository @ WVU with permission from the rights-holder(s). You are free to use this Thesis in any way that is permitted by the copyright and related rights legislation that applies to your use. For other uses you must obtain permission from the rights-holder(s) directly, unless additional rights are indicated by a Creative Commons license in the record and/ or on the work itself. This Thesis has been accepted for inclusion in WVU Graduate Theses, Dissertations, and Problem Reports collection by an authorized administrator of The Research Repository @ WVU. For more information, please contact researchrepository@mail.wvu.edu. 


\title{
Theory of Mind Development and Executive Functioning in Elementary School Children
}

by

Dana Futoran

\section{MASTER'S THESIS}

\author{
Submitted to \\ The Eberly College of Arts and Sciences \\ at West Virginia University \\ in partial fulfillment of the requirements \\ for the degree of \\ Master of Arts \\ in Psychology
}

Anne C. Watson, Chair

Katherine Karraker

Christina Adams

1999

Morgantown, West Virginia

Keywords: Theory of Mind, Executive Function 


\section{ACKNOWLEDGEMENTS}

I would like to express my sincere gratitude to my advisor, Anne Watson, for her unconditional support and understanding. She was always accessible, provided valuable feedback on every aspect of the thesis, and worked with me every step of the way.

I would also like to thank Amy Wilson Strange for giving me the courage to complete the thesis and the opportunity to help her collect the data for her dissertation which became the basis for my thesis.

Finally, I wish to thank my mother for her confidence in me and encouragement to pursue my dreams, my father for his incredible support and to all of my family for their love. 


\section{TABLE OF CONTENTS}

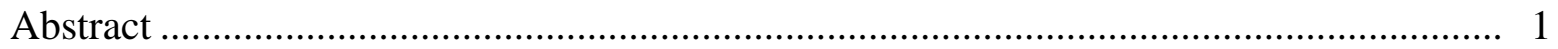

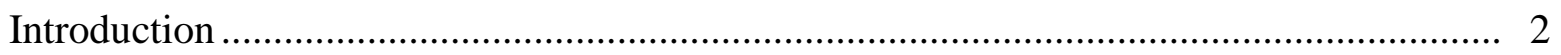

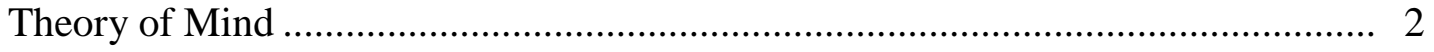

Theory of Mind and Autism........................................................................... 3

Theory of Mind and Verbal Ability .................................................................. 4

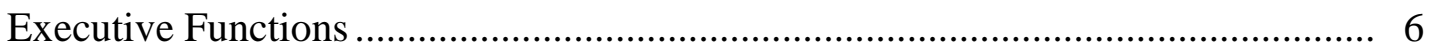

Theory of Mind and Executive Function ........................................................... 8

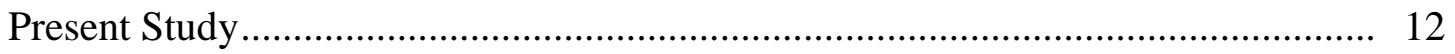

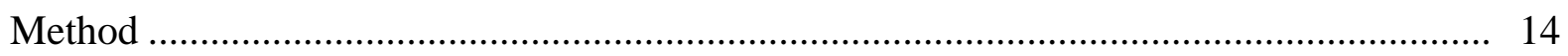

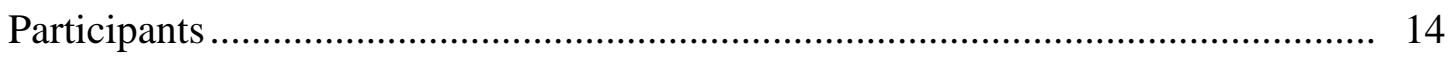

Measures of Cognitive Abilities....................................................................... 14

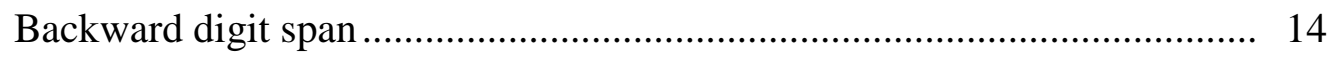

Auditory Language Comprehension ……................................................. 15

Auditory Sentence Memory ………….................................................. 16

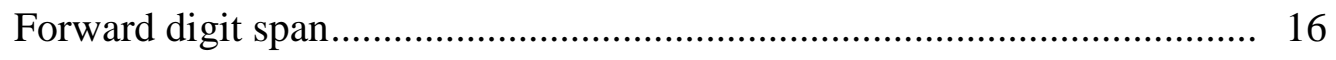

Raven's Colored Progressive Matrices ………………............................. 16

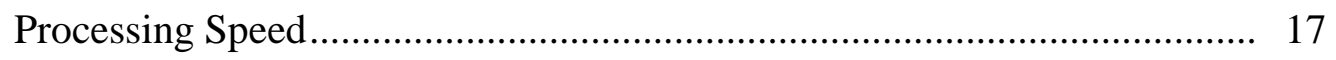

Measures of Theory of Mind.......................................................................... 17

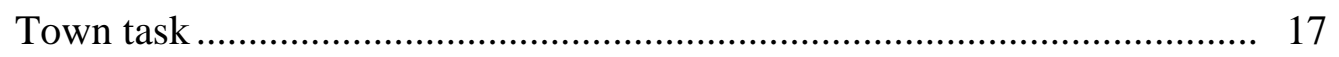

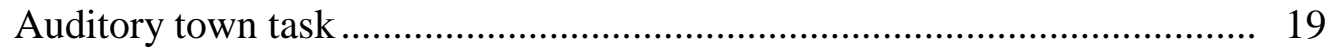

Recursive thinking task ......................................................................... 19

Procedure 
Results

Descriptive Analyses.......................................................................... 21

Correlations between Age and Cognitive and Theory of Mind Variables............... 22

Partial Correlations for Cognitive Measures .................................................... 22

Relatedness and Difficulty of Theory of Mind Tasks ...................................... 23

Partial Correlations for the Cognitive and Theory of Mind Measures................... 23

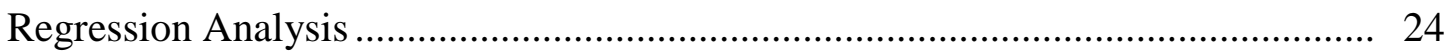

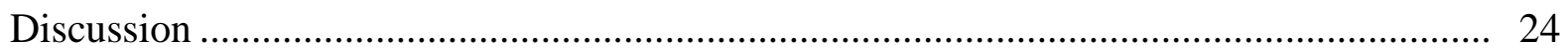

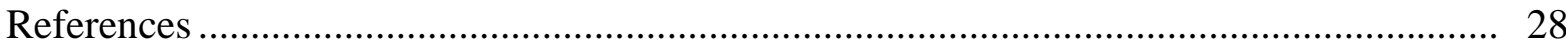

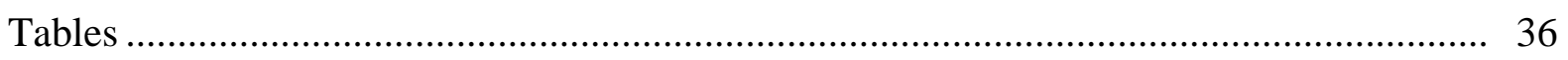

Table 1: Mean, Standard Deviation, and Range for all Variables......................... 36

Table 2: Correlations between Age and the Cognitive and Theory

of Mind Variables............................................................... 37

Table 3: Partial Correlations of Cognitive Measures Controlling for Age .............. 38

Table 4: Partial Correlations of Theory of Mind Measures Controlling for Age ..... 39

Table 5: Partial Correlations between Cognitive and Theory of Mind Measures

Controlling for Age

Table 6: Summary of Multiple Regression Analysis of Variables Predicting

Performance on Recursive Thinking Task

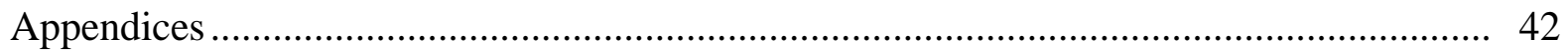

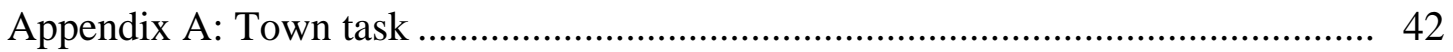

Appendix B: Auditory town task ....................................................... 45

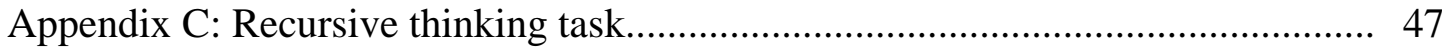




\author{
ABSTRACT \\ Theory of Mind Development and Executive Functioning \\ in Elementary School Children \\ By Dana Futoran
}

The following study explored the role of verbal ability and executive functioning in theory of mind understanding in elementary school children. Scores on measures of language comprehension, verbal ability (sentence memory, and forward digit span), matrix completion, executive functioning (backward digit span), and second-order theory of mind tasks were obtained. Partial correlations of the measures controlling for age revealed verbal ability to be significantly correlated with theory of mind comprehension. A regression analysis demonstrated that auditory language comprehension was the only variable, in addition to age, that explained unique variance in performance on a recursive thinking task. Possible explanations are explored and future directions are recommended. 


\section{Theory of Mind Development and Executive Functioning in Elementary School Children}

Children's ability to describe, predict, and explain human behavior using internal psychological states such as desires, beliefs, and intentions is referred to as a theory of mind (Astington \& Gopnik, 1988; Wellman \& Bartsch, 1988). The majority of research in this area has been done with preschoolers, when children acquire the understanding that people can hold beliefs that are not in accordance with reality ("false beliefs") (e.g., Bartsch \& Wellman, 1989; Lewis \& Osborne, 1990; Wimmer \& Perner, 1983). However, the development of knowledge in this domain most probably entails continuity from the very beginnings of social interactions with caregivers in infancy to more sophisticated and flexible use of mentalistic interpretations of behavior in later childhood. Recently, it has been suggested that executive function deficits may be responsible for constraining theory of mind development until typically developing children reach the age of around four. The present study focuses on the relationship between theory of mind and executive functioning in an elementary school population.

\section{Theory of Mind}

There have been various explanations concerning the origins of a theory of mind (for a review see Moore, 1996). Some have emphasized the importance of the social environment. For example, Russell (1992) and Tomasello (1995) argue that the experience of social interaction provides opportunities for the child to see the outcomes of his or her intentional behavior and the behavior of others. Better understanding of false belief has been found to be related to the number of siblings in the family (Perner, Ruffman, \& Leekham, 1994), the amount of pretense play (e.g., Youngblade \& Dunn, 
1995), the amount of talk about the causal relation between people's beliefs and desires

and their behavior (Brown \& Dunn, 1992; Dunn, 1995), and the quantity of mental verbs used between mothers and children (Moore, Pure, \& Furrow, 1990). The importance of the child's behavior in relation to the social environment has also been considered. For example, "theory-theory" conceptualizations of theory of mind focus on how the child uses his or her own mind as a model to actively generate and test hypotheses about the intentional behavior of others, thus developing a naïve theory of the mind or a "folk" psychology (Gopnik \& Wellman, 1992).

The existence of an innate theory of mind module has also been postulated (Baron-Cohen, 1993). For example, as part of a three-component theory of mind mechanism, Leslie (1987) has posited that a "decoupling device" comes "on-line" at a certain point in brain maturation. This device allows the child to separate what is actually occurring from a representation of what is occurring, thereby enabling symbolic activities like pretend play and false belief understanding (Perner, 1991; see also BaronCohen, 1988). This decoupling is said not to occur in the syndrome of autism (Roth \& Leslie, 1991).

\section{Theory of Mind and Autism}

It has been hypothesized that a lack in theory of mind is responsible for the deficit in individuals with autism (e.g., Baron-Cohen, 1989; Baron-Cohen, Leslie, \& Frith, 1985; Sigman, Arbell, \& Dissanayake, 1995), providing some support for a biological or innate basis for theory of mind development. Autism is a pervasive developmental disorder characterized by impairments in social interaction, communication, and imaginative play (American Psychiatric Association, 1994). Depending on the study, only 15\% to $60 \%$ of 
children with autism are capable of successfully passing standard false belief tasks (Happé, 1995). Identifying differences between those who can pass the theory of mind tasks from those who can not is critical in determining the set of component skills necessary to develop the ability to explain our own and others' behavior using mental concepts. In the classic change in location false belief paradigm by Wimmer and Perner (1983), the child observes "Maxi" put an object in location x and then, when Maxi leaves, watches as the object is transferred from location $\mathrm{x}$ to location $\mathrm{y}$. Since this transfer comes as a surprise, the child has to assume that Maxi still believes that the object is in location x. Children with autism generally respond like normally-developing children under the age of four who have not acquired the appreciation that their thoughts may be different from the doll's beliefs (Baron-Cohen, Leslie, \& Frith, 1985; see Happé \& Frith, 1995, for review). The autistic child will most likely say that when Maxi returns, he will look in location y, despite the fact that Maxi never witnessed the transfer.

\section{Theory of Mind and Verbal Ability}

The potentially critical influence of language and communication skills in general on theory of mind understanding is suggested by these findings and the fact that performance on false belief tasks is related to verbal ability in normally-developing preschoolers. For example, Jenkins and Astington (1996) investigated the role of verbal memory, nonverbal memory, and verbal ability in the development of theory of mind using normally-developing 3- to 5-year-olds. Performance on both a sentence memory task and an expressive language assessment was correlated with false belief understanding, while performance on the nonverbal memory assessment was not. 
Auditory language comprehension has also been found to be related to false belief task performance in preschoolers (Watson, Nixon, Wilson, \& Capage, 1999)

The possibility that verbal skills are related to false belief task performance has also been examined extensively in autistic populations. Happé (1995) found that all autistic individuals with a verbal mental age (VMA) below 5-6 fail theory of mind tasks and all participants with a verbal mental age above an upper threshold of 7-11 pass theory of mind tasks (see also Eisenmajer \& Prior, 1991; Leslie \& Frith, 1988, and Prior, Dahlstrom, \& Squires, 1990). Verbal ability in these studies has been measured by the Peabody Picture Vocabulary Test (Dunn \& Dunn, 1981) and the verbal subscales of standardized tests like the Wechsler Intelligence Scale for Children-III (Weschler, 1991).

Similarly, Yimiya, Slomonica-Levi, Shulman, and Pilowky (1996) attempted to disentangle the effects of chronological age (CA), VMA and performance mental age (PMA) in typically developing, mentally retarded, and autistic children. They were able to match participants on both VMA and PMA. Their results showed that VMA and CA significantly predicted the number of tasks passed by autistic individuals, while PMA did not. Sparrevohn and Howie (1995) also gave autistic participants a performance scale along with verbal and theory of mind tasks. Similar to previous findings, the low verbal ability participants failed a greater number of tasks than the high verbal ability group regardless of performance abilities.

Yet, some autistic adults with high verbal IQ's never acquire a theory of mind (Baron-Cohen, 1989; Sigman, et. al., 1995). Advanced verbal abilities may be necessary, but not sufficient, to develop a theory of mind or compensate for other areas in which the autistic child is impaired. This discrepancy has led researchers to evaluate the role of 
other aspects of cognitive functioning in theory of mind understanding. Specifically, it has been postulated that in addition to verbal ability, a certain level of executive functioning may also be necessary for theory of mind development and may also account for theory of mind deficits in autism.

$\underline{\text { Executive Functions }}$

Conceptualizations of executive function are controversial (see Hughes, 1998a, Zelazo, Carter, Reznick, \& Frye, 1997, and Lyon \& Krasnegor, 1996, for discussions related to developmental issues). According to Barkley (1997), executive functions are defined as "those types of actions we perform to ourselves and direct at ourselves so as to accomplish self-control, goal-directed behavior, and the maximization of future outcomes" (p. 57). In other words, executive function is self-directed behavior used in the storage and manipulation of information. Therefore, executive function deficits can generally be described as unsuccessful complex problem-solving involving response perseveration, an inability to inhibit responses, and difficulty actively manipulating information in an accessible and flexible way. "Without sufficient guidance from working memory, the result is the disproportionate control of behavior by environmental stimuli, and preexisting response tendencies" (p. 191, Kimberg, D’Eposito, \& Farah, 1998).

Most models of executive functions include both verbal and nonverbal components (e.g., the phonological loop and visuospatial sketchpad in Baddeley's (1986) model of working memory). Nonverbal working memory holds nonverbal information like events and behaviors in mind and then acts on these events. Verbal working memory holds verbal information in mind using self-speech and allows the individual to use the 
data for other tasks, and includes the effects of direct instruction and behavior contingent on rules (Barkley, 1997). Nonverbal working memory may be developmentally more primitive than verbal working memory. One study by Conrad (1971) found that children below the age of 5 rely more on visual codes to remember pictures rather than verbal information. In contrast, behavior contingent on rules uses verbal working memory and behavioral inhibition to prevent the unwanted behavior and comply with the rule. By the end of three years, rules become substantially more effective in controlling children's behavior (Barkley, 1997).

There have been a variety of actual tasks that have been called executive function tasks. In the Wisconsin Card Sort Task (WCST, Grant \& Berg, 1948), the participant is asked to sort cards according to a specific rule such as color, shape, or number of objects on the card. During the task, the sorting rule is changed without the participant's knowledge. Participants must inhibit the prepotent response (behavior inhibition), follow a new rule (verbal working memory), maintain self-awareness and hindsight (nonverbal working memory), stay persistent and motivated (self-regulation) and have response flexibility (reconstitution) (Barkley, 1997). All these functions work together to control the motor response of where to place each card. Backward digit span (BDS) is another common task used to measure the capacity of short term working memory, based on a model similar to Baddeley's (e.g., Davis \& Pratt, 1995). BDS requires the individual to hold numbers in working memory and then manipulate these numbers in order to recall them in reverse order. The participant is also required to inhibit a prepotent response (repeating the numbers in the order they were presented), use self-regulation and respond flexibly. 
It has been suggested that the primary deficit in autism is related to executive function (Hughes, 1996; Hughes \& Russell, 1993; Ozonoff, 1995), although, given differences between the behavior of individuals with autism and individuals with prefrontal cortex lesions (who also show executive function deficits), executive dysfunction may be a necessary but not sufficient problem in the development of autism (Ozonoff, 1995). For example, Cieselski and Harris (1997) tested autistic participants on five executive function measures. Performance of the participants on these tests was independent of general intelligence (as measured by the Wechsler Adult Intelligence Scale and Wechsler Intelligence Scale for Children) and was significantly impaired compared to a control group. Errors on the task were characterized as being primarily due to perseveration and difficulty disengaging from irrelevant aspects of the stimuli. This was particularly evident on the tasks with the most loosely defined rules and complex problem-solving (cf. Rumsey \& Hamburger, 1988).

\section{$\underline{\text { Theory of Mind and Executive Function }}$}

From these descriptions of executive functioning it is possible to describe how well-developed executive functioning, particularly with respect to verbal information, may be necessary for developing a theory of mind. For example, the false belief task places the participant in a condition where his or her knowledge conflicts with someone else's knowledge. In order to answer what the other would say, the participant must "disengage" from what he or she knows of the object's true location. For those children who cannot disengage, reality is based on their current belief. This is particularly important when the participant's desire differs from that of the character. For example, Moore, Jarrold, Russell, Lumb, Sapp, and MacCallum (1995) examined the role of 
conflicting desire in false belief task performance. Three- to 5-year-old children were asked to choose one of two animal stickers they would take home in return for doing the study. Then they were told a story about another child who was scared of the particular animal on the sticker they chose. The participant was then asked which sticker he or she thought the story character would choose. Children who were not able to disengage from their own desire picked the same sticker they would like for the story character even though the character was frightened by the sticker.

Similarly, tasks that entail strategic deception have been proposed to assess theory of mind as well as inherently entailing aspects of executive function (Russell, Jarrold, \& Potel, 1994; although see Samuels, Brooks and Frye, 1996, for an alternative interpretation). The "windows task" has been used to assess strategic deception, and is based on Woodruff and Premack's (1979) deception paradigm with chimpanzees. In the task, the participant sits across a table from an opponent. An experimenter has both "players" close their eyes and hides a treat inside one of two opaque boxes placed on the table. The participant is then instructed to point to one of the boxes for the opponent to open. If it is the box with the treat, the opponent gets it. If it is the empty box, the participant gets to open the other one and get the treat. A number of these trials are presented so that the participant learns that the box he or she does not point to will be the one he or she gets to open.

In the test phase, different boxes are used that have windows on the side that faces the participant (i.e., the opponent still cannot see what they contain). Pointing to the empty box will ensure that the participant always gets the treat. Four-year-olds point to the empty box on the first test trial. Typically-developing three-year-olds, autistic 
participants, and non-human primates not only point to the baited box on the first test trial, they continue to point at it on all subsequent trials even though this means they never get the treat. This indicates an inability to disengage from a salient stimulus, inhibit a prepotent response, and behave strategically.

This task continues to be difficult under variations where there is no opponent (hence, no possibility of behaving so as to create a "false belief" in the other), and when the children know where the treat is even if they cannot see it (Russell, et al., 1994). In addition, it is also the case that in one study performance on the windows task was not correlated with performance on standard false belief tasks (Samuels, Brooks, \& Frye, 1996). However, similarities between aspects of theory of mind understanding and executive functioning have been examined more directly, and provide some additional support for linking the two.

Frye, Zelazo, and Palfai (1995) investigated relations between preschoolers' performance on standard theory of mind tasks and a card sorting task. More perseveration errors on the sorting task (which involved a complex embedded rule structure like the WCST) were related to less well-developed false belief reasoning. In another study, Gordon and Olson (1998) had participants do two completely independent tasks at one time (the dual-task paradigm based on Baddeley's model of working memory and executive function (1981)). Children who succeeded on these tasks also did well on the false belief tasks $(\underline{r}=.64)$. Davis and Pratt $(1995)$ found that performance on a backward digit span executive function task was related to theory of mind understanding.

Hughes (1998b) has conducted the most extensive study in this area, looking at both concurrent and longitudinal relations between executive functioning and theory of 
mind. She used tasks that were particularly well-designed with respect to their age appropriateness, for example, the Tower of Hanoi test of executive function was replaced by the Tower of London test (Shallice, 1982, cited in Hughes, 1998b), which reduces demands on cognitive abilities that are not directly related to executive function (like visuomotor coordination and short-term memory). Hughes found significant correlations between the executive function tasks and false belief understanding at both times of measurement (at time 1, the children were approximately 4 years of age, and were one year older at time 2), and predictive relations between executive functioning at time one and theory of mind at time 2. Interestingly, she did not find predictive relations between false belief task performance at time 1 and executive function at time 2 , suggesting that relations between these two types of skills are not caused by a third underlying variable. Rather, the data provide fairly strong support for the idea that executive functioning is a critical factor in false belief understanding but not vice versa. Finally, while age and verbal ability were related to performance on many of the tasks, the majority of the relations she observed between executive function and theory of mind remained significant after age and vocabulary skills were partialled out.

Other studies have specifically demonstrated relations between performance of individuals with autism on executive function and theory of mind understanding (e.g., Pennington \& Ozonoff, 1996; Hughes \& Russel, 1993). Ozonoff, Pennington, and Roberts (1991) compared a group of high-functioning autistic individuals to a control group matched on verbal IQ and CA. All the participants were given a series of tasks measuring theory of mind, including the second-order belief attribution task (town), executive function tasks (Tower of Hanoi and WCST), an emotion perception task, a 
verbal memory task, and a visuospatial ability task. Performance on the executive function and second-order theory of mind tasks was lower for the autistic group than the control compared to any of the other tasks. Questions still remain, however, concerning this issue.

\section{Present Study}

In order to continue investigating relations between theory of mind understanding and executive function, the present study expanded the populations in which these relations have been investigated to elementary school children. As mentioned previously, the majority of work on theory of mind has been done with preschoolers, but understanding in this area continues to grow, and tasks have been developed to tap more sophisticated reasoning in this domain. First, traditional false belief tasks are "firstorder" tasks because they concern one person thinking about another's behavior. However, a critical feature of representational cognition is that it is recursive, and second- and higher-order variations on the original false belief task are possible - he can think about what she is thinking about, not just about what she is doing. The ability to make second-order belief attributions may be a more sensitive measure of theory of mind ability at older ages or higher levels of competence (see also Baron-Cohen, 1989, Ozonoff et al., 1991, and Sparrevohn \& Howie, 1989). Two second-order theory of mind tasks appropriate for use with children ages 5 to 10, a 3-dimensional "town" and a recursive thinking task, were used in the present study. In addition, presenting false belief tasks entirely verbally may also yield some insight into how verbal ability and the verbal working memory aspect of executive functioning are related to theory of mind 
development. Therefore, the town task was also presented in an auditory form, without using 3-dimensional props.

With this older age group, the present study aims to examine relations between verbal abilities, executive function, and theory of mind. Backward digit span was used as the measure of executive function. The Test of Auditory Language ComprehensionRevised (TACL-R) provides a very comprehensive measure of verbal auditory memory skills and assesses children's general language comprehension abilities. Two other measures of verbal auditory memory skills that have been utilized in past research were also included. To assess the relationship between verbal working memory and theory of mind performance, auditory sentence memory and forward digit span were given.

Finally, Raven's Colored Progressive Matrices was used to examine additional verbal and nonverbal skills involved in problem-solving ability (Kleuver, 1995).

In order to provide support for the idea that the links between executive function, verbal ability and theory of mind are not due to development in general intelligence or chronological age, it is important to examine other skills that are not highly related to executive functioning or theory of mind performance, but are related to general intelligence. The processing speed index of the Wechsler Intelligence Scale for ChildrenIII (WISC-III) composed of the Coding and Symbol Search subtests is the index with the lowest correlation with the verbal IQ score (.43), but is correlated with the full scale IQ score or general IQ on the WISC-III (.60; Wechsler, 1991, pp. 270-274) and thus was chosen as a potential non-correlate with executive functioning and theory of mind performance. The two tasks that make up the processing speed index are thought to 
assess aspects of visual attention and concentration and do not involve response perseveration or inhibition, or other aspects of working memory.

Thus, it was hypothesized that the assessments of verbal ability and executive function would be related to performance on the theory of mind tasks, while processing speed would not be related or would be significantly less related to performance on the theory of mind task. The degree to which the measures of executive functioning and the different assessments of verbal ability account for both overlapping and unique variance in the theory of mind measures also was assessed.

\section{Method}

\section{$\underline{\text { Participants }}$}

Participants in the study were 63 elementary school children between the ages of 5 and 10 years $(\underline{\mathrm{M}}=88.79$ months, $\underline{\mathrm{SD}}=14.40$, Range $=65$ to 119 months $)$. The children were predominantly Caucasian and middle-class and attended a local elementary school in Morgantown, WV. A letter providing a description of the study and a request for participation was sent to all the teachers at the school. Over 400 letters were sent home to the families of all children in kindergarten through third grade in the participating school asking the parents for permission to have their children participate in the study. All 63 children whose parents returned the permission form took part in the study.

\section{$\underline{\text { Measures of Cognitive Abilities }}$}

Backward digit span. As the measure of executive function, children listened to a series of numbers of increasing length and then were asked to recall the numbers in the reverse order of presentation. Scores on the backward digit span (BDS) 
are said to represent the ability to hear the sound of the digits presented in a forward manner, maintain the digits in memory, and then reorganize and manipulate the digits in order to repeat them in reverse sequence. (Backward and forward digit span [see below] form the auditory number memory subscale of the Test of Auditory-Perceptual Skills [TAPS]), but were kept separate for the analyses conducted here.) Depending on age, reliability coefficients for internal consistency range from .56 to .77 (Gardner, 1985). As stated by Gardner (1985) content and item validity were found to be sufficient for all six subtests of the TAPS. Correlations between performance of the TAPS and other measures that tap auditory-perceptual skills (e.g., Expressive One-Word Picture Vocabulary Test and the vocabulary subtests of the WISC-III) range from .17 to .56, and indicate that the TAPS does assess aspects of the measured behaviors while also showing unique variance in auditory perception (Gardner, 1985).

Auditory Language Comprehension. As a measure of verbal ability, three scales of the Test for the Auditory Comprehension of Language-Revised (TACL-R; CarrowWoolfolk, 1985) were used to assess children's general language competence: (1) Word Classes and Relations: assesses word meaning and word relations, (2) Morphology: assesses meaning of grammatical morphemes, (3) Sentences: assesses meaning of elaborated sentence constructions. The test was administered according to the procedures in the TACL-R Examiner's Manual (Carrow-Woolfolk, 1985). Each child was presented with a series of three pictures and a verbal prompt, such as a word, phrase, or sentence. The child was then asked to point to the picture that was best described by the utterance. The split-half reliability has been reported to range from .88 to .97 for the total score (Sattler, 1992). As stated by Sattler (1992), the TACL-R appears to have satisfactory 
content validity indicated by an extensive theoretical and logical analysis of language skill development and satisfactory concurrent validity, as shown by significant correlations with similar tests ranging from .37 to .76 (e.g., Peabody Picture Vocabulary Test and the Sequenced Inventory of Communication Development). The raw scores for each of the scales were calculated and converted to standardized scores to account for age differences.

Auditory Sentence Memory. As another measure of verbal ability, this subtest of the TAPS measures ability to recall sentence information by rote memory and correct sequence. Children are read sentences of increasing grammatical complexity and length. Scoring is based on word omission, distortion, substitution, and sequencing error. No reliability was reported for this subtest in the TAPS manual. See backward digit span above for validity of total scores on the TAPS.

Forward digit span. As another measure of verbal ability, children listened to a series of numbers of increasing length and there were asked to recall the numbers in order. In the forward digit span (FDS) test, children were asked to recall the numbers in the same order they heard them. Scores on the FDS are said to measure aspects of rote memory ability and retention of comprehended auditory matter. The reliability coefficients for internal consistency range from .81 to .86 depending on the age of the participant (Gardner, 1985). See backward digit span above for validity of total scores on the TAPS.

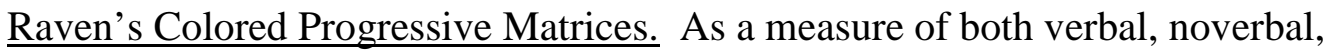
and general intelligence, the Raven's Colored Progressive Matrices measures both verbal and nonverbal problem-solving abilities and general intelligence by asking children to 
match designs to matrices (Raven, Raven, \& Court, 1995). In order to match the matrices, the child may use self-talk to find the piece to fill the matrix. Therefore, it is likely that this task measures verbal working memory as well. There are three different versions of the matrices, the Standard Progressive Matrices, the Advanced Progressive Matrices, and the Colored Progressive Matrices. The Colored Progressive Matrices is the most appropriate for the age range of children who participated in the present study (ages $5-10)$, and has been shown to have test-retest reliability of approximately .90 across all age groups. The Raven's Colored Progressive Matrices has been found to be significantly related to subtest scores and IQs from the WISC-III and significant correlations with the Johnson Test of Achievement-Revised (Kluever, 1995). The colored matrix problems were presented to the children in book form.

Processing Speed. As a measure of general intelligence that is less related to verbal ability than general intelligence, two subtests, Symbol Search and Coding, of the Wechsler Intelligence Scale for Children-III (Weschler, 1991) measured speed of processing. Symbol Search has each child scan through 3 to 5 symbols and determine if any two of the series are the same. Coding requires the child to match a series of symbols with a corresponding number or shape. Each child is given two minutes to complete as many problems as they can. Depending on the age of the participant, testretest reliability coefficients range from .69 to .90 for the two subtests, and .80 to .91 for the processing speed factor (Wechsler, 1991).

\section{Measures of Theory of Mind}

$\underline{\text { Town task A 3-dimensional "town" was constructed using Legos }}{ }^{\mathrm{TM}}$ adapted from a task used by Perner and Wimmer (1985) to examine children's understanding of second 
order beliefs (see Appendix A). The town was made up of two houses, a church, a school, a park, a playground, a road, four 'playpeople,' and an ice-cream van. The entire town fit on a tabletop and could easily be taken apart and reassembled.

The children were told a story that involved two characters named John and Mary. They are in the park when they see an ice cream man. Mary would like to buy an ice cream, but she left her money at home. The ice-cream man says she can get her money and buy some ice cream later, because he will be in the park all afternoon. Mary goes home and John is at the park on his own when he sees the ice cream man leaving the park. John asks the ice cream man where he is going and the man says that he is going to the church. The ice cream man heads down the road towards the church and Mary sees the ice cream man through a window at her house. She asks him where he is going and finds out that he is heading to the church. John goes home to do some homework. Later, he goes over to Mary's house for some help on his homework only to find that she has gone to get an ice cream. After hearing the story, each child is asked a test question, "Where does John think Mary has gone?" a justification question, "Why does he think she has gone to the ___ ? " and three control questions, "Does Mary know that the ice cream van is at the church? Does John know that the ice cream man has talked to Mary? Where did Mary go for her ice cream?" To pass this task and receive 2 points, a child must correctly answer both the test question and the justification question. A correct justification can contain a nesting of epistemic states (e.g., because he does not know that she already knows where the van is), information nested within a belief (e.g., because he does not know that she had talked to the ice-cream man), or refer to the initial location of the ice cream van (e.g., because she said she would go to the park to get ice cream in the 
afternoon). If the child answered the test question correctly, but failed to answer the justification question correctly, he or she only received 1 point. Finally, if the test question was answered incorrectly (the justification would be insignificant if the test question was wrong), then the child received no points. Three control questions were used to ensure that the child understood the story and no points were given for correct answers. For example, "Does Mary know that the ice-cream van is at the church?" Therefore, a range of 0 to 2 total points was possible for the Town task.

Auditory town task The children received one story that paralleled the "ice cream story" used in the Town task described above (see Appendix B). The character names and the situations were changed (e.g., Jenny and Eric are at the zoo and Jenny wants to buy some lemonade). Rather than enacting the story using dolls, legos, or other props, this story was told entirely verbally. The Auditory town task was scored the same way as the Town task with a total of 2 possible points.

$\underline{\text { Recursive thinking task }}$ This task was adapted from Openheimer (1986) and Miller, Kessel, and Flavell (1970). During this task, the participants were shown a series of cartoon people and thought bubbles, to examine the child's ability to reason about embedded thoughts. First, the children were introduced to the four characters (father, mother, boy, and girl) and the concepts of thought bubbles and talking bubbles. When the child could correctly name both the characters and the bubbles, the Recursive thinking task was given (see Appendix C).

There were 18 cards that depicted four different types of thinking: (1) contiguity, an individual thinking about him or herself or others, (2) action, thinking about individuals participating in actions, (3) one-loop recursion, thinking about someone else's 
thoughts, and (4) two-loop recursion, thinking about someone else who is thinking about someone else. There were six cards depicting contiguity, three of action, five of one-loop recursion, and four of two-loop recursion. All 18 cards were randomly scattered on the table facing up and towards the child. Then he or she was asked to point to the card which described one of the thought processes (e.g., Point to the card of the boy thinking about the girl thinking about the father?). If the child pointed to the correct card, he or she received 1 point, making a total of 18 points possible. All of the cards remained on the table throughout the 18 items.

\section{$\underline{\text { Procedure }}$}

The data were collected as part of a larger study on attentional processes and theory of mind development in school children. Each participating child was brought out of the classroom for two to three sessions ranging from fifteen to twenty-five-minutes to receive the Raven's Colored Progressive Matrices (Raven, Raven, \& Court, 1995), Test of Auditory Comprehension of Language-Revised (Carrow-Woolfolk, 1985), Symbol Search and Coding subtests of the Wechsler Intelligence Scale for Children-III (Wechsler, 1991), Test of Auditory-Perceptual Skills (which included auditory sentence memory and forward and backward digit span; Gardner, 1985) and the various theory of mind measures as well as other tasks required for the larger study. The testing occurred in a small conference room in the school office to allow for maximum privacy. Two graduate and two undergraduate students were trained in task administration by a doctoral student who had experience doing assessments and all five students conducted the testing. Each participant was tested by one or more testers and received all of the tests in random order with the exception of the Auditory town task which was added later in the 
study after all participants had already received the Town task. The potential of practice effects resulting in increased scores on the Auditory town was assessed.

Results

Data for each measure was first examined descriptively for distributions and univariate outliers. Next, partial correlations for all of the cognitive ability variables and the theory of mind measures controlling for age were examined separately. Then, partial correlations between the cognitive ability variables and the theory of mind measures controlling for age were examined. Finally, multiple regression analyses were conducted to assess shared and unique variance in predicting the theory of mind measures from any cognitive correlates that demonstrated explanatory power (i.e., were significantly correlated to the theory of mind measures at the zero-order level).

To determine whether differences existed between boys and girls, t-tests comparing the performance of boys and girls for each measure were conducted. No gender differences were found. Therefore, all subsequent analyses were collapsed across gender.

\section{Descriptive Analyses}

Table 1 shows the mean, standard deviation, and range of each of the variables in the present study. These data were examined for their distributions and for any univariate and bivariate outliers. All variables met acceptable criteria for inclusion in further analyses. Three children were missing data on the Town task and Auditory town task and nine children were missing processing speed data, because they no longer could participate in the study. Missing data points for the town tasks were replaced with the mean across participants. However, because there was a large number of participants 
missing data for processing speed, analyses involving processing speed utilized only the 52 children with complete data. One individual consistently scored lower than the other participants on all tasks. Initial correlations including this participant were compared to correlations that excluded the individual and no significant differences were found. Therefore, analyses reported include this participant.

\section{Correlations between Age and Cognitive and Theory of Mind Variables}

Correlations were obtained between age and the raw scores of the cognitive variables (processing speed, problem-solving, auditory language comprehension, auditory sentence memory, and forward and backward digit span) and the theory of mind variables (Town task, Auditory town task, and Recursive thinking task) (see Table 2). Age was significantly and positively associated with all of the raw scores of the cognitive variables except for processing speed (sum of Coding and Symbol Search subtests of WISC-III). Age was also significantly and positively correlated with the three theory of mind measures.

\section{Partial Correlations of Cognitive Measures}

Partial correlations controlling for age were computed for the raw scores of processing speed (sum of the Coding and Symbol Search subtests of the WISC-III), problem-solving ability, auditory language comprehension, auditory sentence memory, forward digit span, and backward digit span (see Table 3). Better auditory language comprehension was associated with higher scores on processing speed, problem solving, sentence memory, and backward digit span. Higher scores on backward digit span were associated with problem-solving ability in contrast to scores on forward digit span that 
were not related to problem-solving. Intercorrelations between all four verbal measures were positive, however one did not meet significance.

\section{$\underline{\text { Relatedness and Difficulty of Theory of Mind Tasks }}$}

Partial correlations for the three theory of mind tasks controlling for age were obtained (see Table 4). Better scores on the Town task were associated with high scores on the Auditory town task. Scores on the Recursive thinking task were not related to either of the town tasks. A t-test showed that the Town task (mean $=.88$ ) was not significantly harder than the Auditory town task $($ mean $=.97)(\underline{t}=.61, \underline{p}<.54)$ and therefore the possibility that practice effects significantly elevated scores on the Auditory town task is unlikely.

Partial Correlations of the Cognitive and Theory of Mind Measures Controlling for Age

As shown in Table 5, correlations were conducted between each of the cognitive measures (processing speed, problem-solving, auditory language comprehension, auditory sentence memory, forward digit span, and backward digit span) and theory of mind tasks (Town task, Auditory town task, and Recursive thinking task) controlling for age. High scores on the Town task were associated lower scores on processing speed, but not related to scores on any of the other cognitive measures. The Auditory town task was also not related to any of the cognitive measures. Better scores on the Recursive thinking task were associated with better problem-solving, language comprehension, sentence memory, and backward digit span, but not related to scores on forward digit span or processing speed. 


\section{$\underline{\text { Regression Analysis }}$}

One regression analysis was conducted to determine the amount of independent variance in performance on the Recursive thinking task that was explained by only those cognitive variables with which it was significantly correlated: problem-solving ability, auditory language comprehension, auditory sentence memory, and backward digit span. Age was entered on the first step, and accounted for $18.5 \%$ of the variance in performance on the Recursive thinking task $(\underline{\mathrm{F}}(1,56)=12.48 . \underline{\mathrm{p}}<.00)$. Problem-solving ability, auditory language comprehension, auditory sentence memory and forward and backward digit span were entered together on the second step, and the final regression equation accounted for $64.0 \%$ of the variance in performance on the Recursive thinking task $(\underline{\mathrm{F}}(5,56)=18.17, \underline{\mathrm{p}}<.00)$. Only the beta weight for auditory language comprehension $(.73, \underline{p}<.00)$ was significant in the final equation.

\section{Discussion}

The present study investigated the role of verbal ability, processing speed, and executive function in children's theory of mind understanding. Past research has focused on preschoolers, during the time when false belief understanding begins to emerge. This study utilized tasks appropriate for elementary school children and measured more advanced forms of theory of mind involving recursive, second- and higher-order processes. The results of this study indicated that verbal ability and executive function continue to be important skills for theory of mind development as children reach more advanced levels of theory of mind performance. This finding is bolstered by the fact that another important measure of cognitive ability, processing speed, was not predictive of theory of mind functioning. 
Age was significantly correlated with performance on all three theory of mind tasks. These findings confirm the developmental progression of theory of mind understanding throughout elementary school. Rather than being a concept that is acquired around age four when children usually gain false belief understanding, theory of mind development appears to continue to grow past the preschool years.

Past studies have found language ability was related to performance on theory of mind tasks in typically-developing preschoolers and children with autism. This research has utilized a variety of measures of language. The present study included two measures used in past research, auditory sentence memory and forward digit span, and two new measures, TACL-R and Raven's Colored Progressive Matrices. Auditory language comprehension as measured by the TACL-R was the only language measure that was positively and significantly related to performance on all three measures of theory of mind. Furthermore, in the regression analysis, TACL-R, in addition to age, was the only significant predictor of performance on the Recursive thinking task. Other research has found relationships between executive functioning and theory of mind after controlling for language skills as measured by vocabulary tests. This study was the first to include multiple assessments of complex verbal skills, including verbal auditory memory and comprehension of grammatical morphemes and elaborated sentence constructions. The only measure of verbal skills that was less correlated with theory of mind than the measure of executive function, BDS was FDS. This finding is similar to the results Davis and Pratt (1995) found with 3- to 5-year olds. Davis and Pratt's study revealed that backward digit span significantly predicted performance on a false belief task and a false photograph task, but forward digit span did not. The results of both the Davis and Pratt 
study and the present study add to the increasing evidence in support that verbal working memory is important in predicting theory of mind performance. The amount of information (i.e., the number of digits) that the child can hold and manipulate in verbal working memory (recall in reverse order) while inhibiting the prepotent response (recall in the same order as presented) is significantly related to theory of mind performance. Unlike backward digit span, forward digit span only requires the participant to hold the numbers in same order as they were presented and then recall them with no manipulation required. The present study, therefore, suggests complex relations between the various measures of verbal ability, the BDS task, and the theory of mind tasks.

A limitation of the present study is that a vocabulary test like the Test of Early Language Development (Hresko, Reid, \& Hammill, 1981) or the Peabody Picture Vocabulary Test (Dunn \& Dunn, 1981) was not included to compare results with previous studies and examine the relationship between vocabulary tests, complex verbal skills as measured by the TACL, executive functioning, and performance on theory of mind tasks. In addition, the sample consisted of children from predominantly white, middle class families. Many of the children who participated were also involved in gifted programs or had been diagnosed with Attention-Deficit Disorder.

Future research with elementary school children should use other measures of executive function that have been used previously with preschoolers and children with autism, such as a Wisconsin Card Sorting Task (Frye, Zelazo, and Palfai, 1995) or the "windows task" (Russell, et al., 1994), in order to further investigate relations between complex verbal comprehension skills and executive function in predicting theory of mind developmet. In addition, different measures of advanced forms of theory of mind should 
be utilized. It is important to determine the similarities and differences between the various executive functioning tasks, verbal tasks, and theory of mind. In addition, studies of other populations with different social and cultural backgrounds using these types of tasks have been largely overlooked. Varying qualities of social interaction, exposure to mentalistic concepts and use of executive functioning may play a large role in theory of mind development.

As stated by Hughes (1998a), children's theories of mind are multifaceted constructs, and involve several distinct types of skill. Individual children most likely develop an understanding of mental states by way of different pathways involving various precursors. Frith, Morton, and Leslie (1991) have also hypothesized that theory of mind acquisition most likely occurs via multiple pathways, through their work with the autistic population. The present study supports that throughout elementary school, typically developing children continue to gain theory of mind understanding with advances in both verbal ability and executive functioning. 


\section{References}

American Psychiatric Association. (1994). Diagnostic and statistical manual of mental disorders (4th ed.). Washington, DC: Author.

Astington, J.W., \& Gopnik, A. (1988). Knowing you've changed your mind: Children's understanding of representational change. In J. W. Astington, P. L. Harris, \& D. R. Olson (Eds.), Developing Theories of Mind (pp. 193-206). Cambridge: Cambridge University Press.

Astington, J.W., \& Jenkins, J. M. (1995). Theory of mind development and social understanding. Cognition and Emotion, 9, 151-165.

Baddeley, A. (1986). Working memory. Oxford, UK: Oxford University Press.

Barkley, R.A. (1997). ADHD and the nature of self-control. New York: Guilford Press.

Baron-Cohen, S. (1989). The autistic child's theory of mind: a case of specific developmental delay. Journal of Child Psychology and Psychiatry, 30, 285-297.

Baron-Cohen, S. (1993). From attention-goal psychology to belief-desire psychology. The development of a theory of mind and its dysfunction. In S. BaronCohen, H. Tager-Flusberg, \& Cohen, D. (eds.), Understanding other minds: Perspectives from autism. Oxford, UK: Oxford University Press.

Baron-Cohen, S., Leslie, A. M., \& Frith, U. (1985). Does the autistic child have a "theory of mind"? Cognition, 21, 37-46.

Bartsch, K. \& Wellman, H. (1989). Young children's attribution of action to beliefs and desires. Child Development, 60, 946-964.

Brown, J. \& Dunn, J. (1992). Talk With Your Mother or Your Sibling? 
Developmental changes in early family conversations about feelings. $\underline{\text { Child }}$ Development, 63, 336-349.

Carrow Woolfolk, A. (1985). The Test for Auditory Comprehension of

Language-Revised. Riverside Publishing

Ciesielski, K. T., \& Harris, R. J. (1997). Factors related to performance failure on executive tasks in autism. Child Neuropsychology, 3(1), 1-12.

Conrad, R. (1971). The chronology of the development of covert speech in children. Developmental Psychology, 5, 398-405.

Davis, H. L., \& Pratt, C. (1995). The development of children's theory of mind: The working memory explanation. Australian Journal of Psychology, 47(1), 25-31.

Dunn, J. (1995). Children as psychologists: The later correlates of individual differences in understanding of emotions and other minds. Cognition and Emotion, 9, 187-201.

Dunn, L. M., \& Dunn, L. M. (1981). Manual for the Peabody Picture Vocabulary Test - Revised. Circle Pines, MN: American Guidance Service.

Eisenmajer, R., \& Prior, M. (1991). Cognitive linguistic correlates of "theory of mind" ability in autistic children. British Journal of Developmental Psychology, 9, 351364.

Frith, U., Morton, J., \& Leslie, A. M. (1991). The cognitive bias of a biological disorder: Autism. Trends in Neurosciences, 14, 433-438.

Frye, D., Zelazo, P. D., \& Palfai, T. (1992). Theory of mind and rule-based reasoning. Cognitive Development, 10, 483-527. 
Gardner, M.F. (1985). Test of Auditory-Perceptual Skills. Burlingame, CA: Psychology and Educational Publications, Inc.

Gopnik, A., \& Wellman, H. (1992). Why the child's theory of mind really is a theory. Mind and Language, $7,145-171$.

Gordon, A. C., \& Olson, D. R. (1998). The relation between acquisition of TOM and the capacity to hold in mind. Journal of Experimental Child Psychology, 68(1), 7083.

Grant, D.A., \& Berg, E.A. (1948). A behavioral analysis of degree of reinforcement and ease of shifting to new responses in a Weigl-type card sorting problem. Journal of Experimental Psychology, 38, 404-411.

Happé, F. (1995). The role of age and verbal ability in the theory of mind task performance of subjects with autism. Child Development, 66, 843-855.

Happé, F., \& Frith, U. (1995). Theory of mind in autism. In E. Schopler \& G.B. Mesibov (Eds.), Learning and cognition in autism (pp. 177-197). New York: Plenum Press.

Hresko, W. P., Reid, D. K., \& Hammill, D. D. (1981). The Test of Early Language Development. Austin, TX: Pro-Ed.

Hughes, C. (1996). Control of action and thought: Normal development and dysfunction in autism. Journal of Child Psychiatry and Psychology, 37, 229-236.

Hughes, C. (1998a). Executive function in preschoolers: Links with theory of mind and verbal ability. British Journal of Developmental Psychology, 16, 233-253. 
Hughes, C. (1998b). Finding your marbles: Does preschoolers' strategic behavior predict later understanding of mind? Developmental Psychology, 34, 13261339.

Hughes, C., \& Russell, J. (1993). Autistic children's difficulty with mental disengagement from an object: Its implications for theories of autism. Developmental Psychology, 29, 498-510.

Jenkins, J. M., \& Astington, J. W. (1996). Cognitive factors and family structure associated with theory of mind development in young children. Development Psychology, 32, 70-78.

Kimberg, D.Y., D’Esposito, M., \& Farah, M.J. (1998). Cognitive functions in the prefrontal cortex -working memory and executive control. $\underline{\text { Current Directions in }}$ Psychological Science, 6, 185-192.

Kluever, R. C. (1995). The WISC-III and Raven Colored Progressive Matrices Test: A pilot study of relationships. Paper presented at the meeting of the American Educational Research Association, San Francisco, CA.

Leslie, A. (1987). Presence and representation: The origins of a "theory of mind." Psychological Review, 94, 412-426.

Leslie, A., \& Frith, U. (1988). Autistic children's understanding of seeing, knowing, and believing. British Journal of Developmental Psychology, 6, 315-324.

Lewis, C., \& Osborne, A. (1990). Three-year-olds' problems with false belief: Conceptual deficit or linguistic artifact? Child Development, $\underline{61}, 1514-1519$.

Lyon, G.R., \& Krasnegor, N.A. (Eds.) (1996). Attention, memory, and executive function. Baltimore, MD: P.H. Brookes Publishing Co. 
Miller, P., Kessel, F., \& Flavell, J. (1970). Thinking about people thinking about people thinking about...: A study of social cognitive development. Child Development, 41, 613-623.

Moore, C. (1996). Evolution and modularity of mindreading. Cognitive Development, 10, 605-621.

Moore, C., Jarrold, C., Russel, J., Lumb, A., Sapp, F., \& MacCallum, F. (1995). Conflicting desire and the child's theory of mind. Cognitive Development, 10, 467-482.

Moore, C., Pure, K., \& Furrow, D. (1990). Children's understanding of the modal expression of certainty and uncertainty and its relation to the development of a representational theory of mind. Child Development, 61, 722-730.

Openheimer, L. (1986). Development of recursive thinking: Procedural variations. Child Development, 41, 613-623.

Ozonoff, S. (1995). Executive functions in autism. In E. Schopler \& G.B. Mesibov (Eds.), Learning and Cognition in autism (pp. 199-219). New York: Plenum Press.

Ozonoff, S., Pennington, B.F., \& Rogers, S.J. (1991). Executive function deficits in high-functioning autistic individuals: Relationship to theory of mind. Journal of Child Psychiatry and Psychology, 32, 1081-1105.

Pennington, B.F., \& Ozonoff, S. (1996). Executive function and developmental psychopathology. Journal of Child Psychology and Psychiatry, 37, 51-87.

Perner, J. (1991). Understanding the representational mind. Cambridge, MA: The MIT Press. 
Perner, J., Ruffman, T., \& Leekam, S. R. (1994). Theory of mind is contagious: You catch it from your sibs. Child Development, 65, 1228-1238.

Perner, J. \& Wimmer, H. (1985). 'John thinks that Mary thinks that' Attribution of second-order beliefs by 5-10 year old children. Journal of Experimental Child Psychology, 39, 437-471.

Prior, M., Dahlstrom, B., \& Squires, T.L. (1990). Autistic children's knowledge of thinking and feeling states in other people. Journal of Child Psychology and Psychiatry, 31, 587-601.

Roth, D., \& Leslie, A.M. (1991). The recognition of attitude conveyed by utterance: A study of preschool and autistic children. British Journal of Developmental Psychology, 9, 315-330.

Rumsey, J.M., \& Hamburger, S.D. (1988). Neuropsychological findings in highfunctioning autistic men with infantile autism, residual state. Journal of Clinical and Experimental Neuropsychology, 10, 201-221.

Russell, J. (1992). The theory theory: So good they named it twice. Cognitive Development, 7, 485-519.

Russell, J., Jarrold, C., \& Potel, D. (1994). What makes strategic deception difficult for children—-the deception or the strategy? British Journal of Developmental Psychology, 12, 301-314.

Samuels, M.C., Brooks, P.J., \& Frye, D. (1996). Strategic game playing in children through the windows task. British Journal of Developmental Psychology, 14, $159-172$. 
Sattler, J.M. (1992). Assessment of academic achievement and special abilities. Assessment of Children. (pp. 328-358). San Diego, CA: J.M. Sattler, Publisher, Inc.

Siegal, M., \& Beattie, K. (1991). Where to look first for children's knowledge of false beliefs. Cognition, 38, 1-12.

Sigman, M., Arbell, S., \& Dissanayake, C. (1995). Current research findings on childhood autism. Canadian Journal of Psychiatry, 40, 289-294.

Sparrevohn, R., \& Howie, P.M. (1995). Theory of mind in children with autistic disorder: Evidence of developmental progression and the role of verbal ability. Journal of Child Psychology and Psychiatry, 36, 249-263.

Tomasello, M. (1995). Joint attention as social cognition. In C. Moore, \& Dunham, P. J. (Eds.), Joint Attention: Its Origins and Role in Development (pp.103-130). Hilldale, NJ: Lawrence Erlbaum Associates.

Watson, A.C., Nixon, C.L., Wilson, A., \& Capage, L. (1999). Social interaction skills and theory of mind in young children. Developmental Psychology.

Wechsler, D. (1991). Weschler Intelligence Scale for Children-Third Edition. San Antonio, TX: Harcourt, Brace, Jovanovich, Inc.

Wellman, H.M., \& Bartsch, K. (1988). Young children's reasoning about beliefs. Cognition, 31, 239-277.

Wimmer, H., \& Perner, J. (1983). Beliefs about beliefs: Representation and the constraining function of wrong beliefs in young children's understanding of deception. Cognition, $\underline{13}, 103-128$.

Woodruff, G., \& Premack, D. (1979). Intentional communication in the chimpanzee: The development of deception. Cognition, 7, 333-362. 
Yirmiya, N., Solomonica, D., Shulman, C., \& Pilowsky, T. (1996). Theory of mind in individuals with autism, Down syndrome and mental retardation of unknown etiology: The role of age and intelligence. Journal of Child Psychology and Psychiatry, 37, 1003-1014.

Youngblade, L. \& Dunn, J. (1995). Individual differences in young children's pretend play with mother and sibling: Links to relationships and understanding of other people's feelings and beliefs. Child Development, 66, 1472-1492.

Zelazo, P. D., Carter, A., Reznick, J, \& Frye, D. (1997). Early development of executive function: A problem-solving framework. Review of General Psychology, 1(2), 198-226. 
Table 1

$\underline{\text { Mean, Standard Deviation, and Range for all Variables }}$

\begin{tabular}{llll}
\hline Variables & $\underline{\mathrm{M}}$ & $\underline{\mathrm{SD}}$ & $\underline{\text { Range }}$ \\
\hline Processing speed & 21.79 & 5.51 & $12.00-36.00$ \\
Problem-solving & 22.35 & 6.59 & $8.00-35.00$ \\
Auditory language comprehension & 101.79 & 12.10 & $66.00-120.00$ \\
Auditory sentence memory & 4.74 & 1.52 & $1.00-7.00$ \\
Forward digit span & 26.82 & 11.22 & $4.00-62.00$ \\
Backward digit span & 9.79 & 4.91 & $.00-28.00$ \\
Town task & .88 & .95 & $.00-2.00$ \\
Auditory town task & .97 & .93 & $.00-2.00$ \\
Recursive thinking task & 10.25 & 4.30 & $2.00-18.00$ \\
\hline
\end{tabular}


Table 2

Correlations between Age and the Cognitive and Theory of Mind Variables

Age

Cognitive Variables

Processing speed

.094

Problem-solving

$.57 * *$

Auditory language comprehension

$.62 * *$

Auditory sentence memory

$.43^{* *}$

Forward digit span

$.36^{* *}$

Backward digit span

$.43 * *$

Theory of Mind Variables

Town task

$.30 *$

Auditory town task

$.28 *$

Recursive thinking task

$.44 * *$

$* \mathrm{p}<.05$.

$* * \underline{p}<.01$. 
Table 3

$\underline{\text { Partial Correlations of Cognitive Measures Controlling for Age }}$

$\begin{array}{lllll}1 & 2 & 3 & 4 & 5\end{array}$

1. Processing speed

2. Problem-solving . $31 *$

3. Language comp. $.30 * \quad .54 * *$

4. Sentence mem. $\quad-.079 \quad .27 * \quad .29 *$

$\begin{array}{lllll}\text { 5. FDS } & -.14 & .061 & .15 & .54 * *\end{array}$

$\begin{array}{llllll}\text { 6. BDS } & -.022 & .34 * * & .32 * * & .47 * * & .29 *\end{array}$

$* \underline{p}<.05$, one-tailed.

$* * \mathrm{p}<.01$, one-tailed. 
Table 4

Partial Correlations of Theory of Mind Measures Controlling for Age

1

1. Town task

2. Auditory town task $.29 * *$

3. Recursive thinking task $\quad .10 \quad .17$

$* \mathrm{p}<.01$, one-tailed. 
Table 5

Partial Correlations for Cognitive and Theory of Mind Measures Controlling for Age

$\begin{array}{lll}\text { Town } & \begin{array}{l}\text { Auditory } \\ \text { town }\end{array} & \begin{array}{l}\text { Recursive } \\ \text { thinking }\end{array}\end{array}$

$\begin{array}{llll}\text { 1. Processing speed } & -.33 * & -.075 & .089\end{array}$

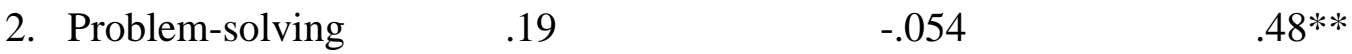

3. Language comprehension .11 . $12 \quad .69 * *$

4. Sentence memory $\quad-.090 \quad-.17 \quad .34^{*}$

$\begin{array}{llll}\text { 5. Forward digit span } & .048 & -.081 & .14\end{array}$

$\begin{array}{llll}\text { 6. Backward digit span } & .095 & -.092 & .31\end{array}$

$* \underline{p}<.05$, one-tailed.

$* * \mathrm{p}<.01$, one-tailed. 
Table 6

$\underline{\text { Summary of Multiple Regression Analysis of Variables Predicting Performance on }}$

$\underline{\text { Recursive Thinking Task }}$

\begin{tabular}{|c|c|c|c|c|}
\hline Independent Variable & $\mathrm{B}$ & SE B & Beta & Final $\mathrm{R}^{2}$ \\
\hline \multicolumn{5}{|l|}{ Step 1} \\
\hline Age & .13 & .037 & $.43 * *$ & \\
\hline \multicolumn{5}{|l|}{ Step 2} \\
\hline Problem-solving & .067 & .099 & .062 & \\
\hline Language comprehension & .26 & .048 & $.73 * *$ & \\
\hline Sentence memory & .47 & .39 & .13 & \\
\hline Backward digit span & .011 & .10 & .012 & .64 \\
\hline
\end{tabular}

$* * \underline{p}<.01$. 
Appendix A

Town task 
Date Tester Score

\title{
False Belief Version of Ice Cream Story
}

\author{
Introduction
}

This is a story about John and Mary who live in this village. This morning John and Mary are together in the park. In the park there is also an ice-cream man in his van.

\section{Episode 1}

Mary would like to buy an ice cream cone but she left her money at home. So she is very sad. "Don't be sad," says the ice-cream man, "you can fetch your money and buy some ice cream later. I'll be here in the park all afternoon." "Oh good," says Mary, I'll be back in the afternoon to buy some ice cream. I'll make sure I won't forget my money then."

\section{Episode 2}

So Mary goes home.... She lives in this house. She goes inside the house. Now John is on his own in the park. To his surprise he sees the ice-cream man leaving the park in his van. 'Where are you going?" asks John. The icecream man says "I'm going to drive my van to the church. There is no one in the park to buy ice-cream; so perhaps I can sell some outside the church."

\section{Episode 3}

The ice-cream man drives over to the church. On his way he passes Mary's house. Mary is looking out the window and spots the van. "Where are you going?" she asks. "I'm going to the church. I'll be able to sell more ice cream there," answers the man. "It's a good thing that I saw you." says Mary. Now John doesn't know that Mary talked to the ice-cream man. He doesn't know that!

\section{Episode 4}

Now John has to go home. After lunch he is doing his homework. He can't do one of the tasks. So he goes over to Mary's house to ask for help. Mary's mother answers the door. "Is Mary in?" asks John. "Oh," says Mary's mother, "She lust left. She said she was going to get an ice cream cone."

\section{Test Question}

So John runs to look for Mary. Where does he think she has gone?

\section{Justification question}

Why does he think she has gone to the ?

If correct $=3$ POINTS, continue with disappear story; If incorrect $=0$ POINTS, continue with Memory aid and Prompt story

1.

\section{Control Questions}

Does Mary know that the ice-cream van is at the church?

Does John know that the ice-cream man has talked to Mary?

Where did Mary go for her ice cream? 


\section{Criteria for Justification Question}

A. Correct Justifications

- "Belief-belief": Contain nestings of epistemic states, e.g.: "Because he doesn't know that she already knows where the van is."

- "Belief-information": An information statement nested within a belief, e.g.: "Because he doesn't know that she had talked to (seen) the ice cream man."

- "Initial Location": Refers to the initial location of the ice-cream van, e.g., "Because she had said that in the afternoon she would go to the park to buy ice cream."

B. Incorrect Justifications

- "First-order Beliefs": Refers to relevant events for either John's or Mary's state of knowledge, e.g., "Because the ice-cream man told John and Mary that he' $d$ be at the church."

- "Zero-order strategy": Refers to the critical object's current location, e.g., "Because the ice-cream van is that church."

- Various answers 
Appendix B

Auditory town task 


\section{False Belief Music Story (auditory story, no visuals)}

This is a story about Robbie and Kate. It is a Saturday afternoon and Robbie and Kate are at the mall listening to a band playing music.

Scene 1 (Robbie and Kate are at the mall listening. to a band)

Robbie wants to play with them, but he has left his guitar at home. He is very upset. "Don't be upset" says the bandleader. "You can get your guitar and play with us later, because we will be here at the mall all afternoon." "Oh good," says Robbie "I'll be back later to play with you, and I'll be sure not to forget my guitar."

Scene 2 (Robbie at home, Kate at the mall)

So Robbie goes home. Now Kate is at the mall by herself. To her surprise, she sees the band leaving the mall with their instruments. "Where are you going?" she asks. The bandleader says, "We're going to go to a restaurant. There is no one here at the mall to listen to us, so maybe we can play for the people in the restaurant."

Scene 3 (The band drives past Robbie's house on the way to the restaurant)

The band is driving to the restaurant when they pass Robbie's house. Robbie is looking out of the window and sees the band in their van. He runs outside. "Where are you going?" he asks. "We're going to the restaurant. We will be able to play for more people there," answers the bandleader ."It's a good thing I saw you," says Robbie. However, Kate does not know that Robbie talked to the bandleader. She doesn't know that!!

\section{Scen e4 (Robbie and Kate's houses]}

It is a little later, and Kate goes home to make lunch. She is out of bread, so she walks to Robbie's house to ask if she can borrow some. Robbie's mother answers the door. "Is Robbie home?" asks Kate. "Oh," says Robbie's mother, "He just left. He said he was going to play his guitar with the band."

\section{TEST QUESTION}

Kate runs to look for Robbie. Where does she think he has gone?

\section{JUSTIFICATION QUESTION}

Why does she think he has gone to the $?$

\section{CONTROL QUESTIONS}

1. Does Robbie know that the band is at the restaurant?

2. Does Kate know that the bandleader has talked to Robbie?

3. Where did Robbie go to play with the band? 
Appendix C

Recursive thinking task 
Contiguity:

$\begin{array}{ll}1 & \text { The boy is thinking of the girl } \\ 2 & \text { The boy is thinking of himself } \\ 3 & \text { The boy is thinking of the girl and father } \\ 4 & \text { The boy is thinking of himself and the girl } \\ 5 & \text { The boy is thinking of the girl, father, and mother } \\ 6 & \text { The boy is thinking of himself, the girl, and father }\end{array}$

Action:

$7 \quad$ The boy is thinking that the girl is talking to father

8 The boy is thinking that he is talking to the girl

9 The boy is thinking that the girl is talking to him

One-loop Recursion:

10

11

12

13

14

The boy is thinking that the girl is thinking of father The boy is thinking that he is thinking of the girl The boy is thinking that the girl is thinking of him The boy is thinking that the girl is thinking of herself The boy is thinking that he is thinking of himself

Two-loop Recursion:

The boy is thinking that the girl is thinking of the father thinking of mother thinking of herself

The boy is thinking that the girls is thinking of him thinking of her

8 The boy is thinking that he is thinking of himself thinking of himself 


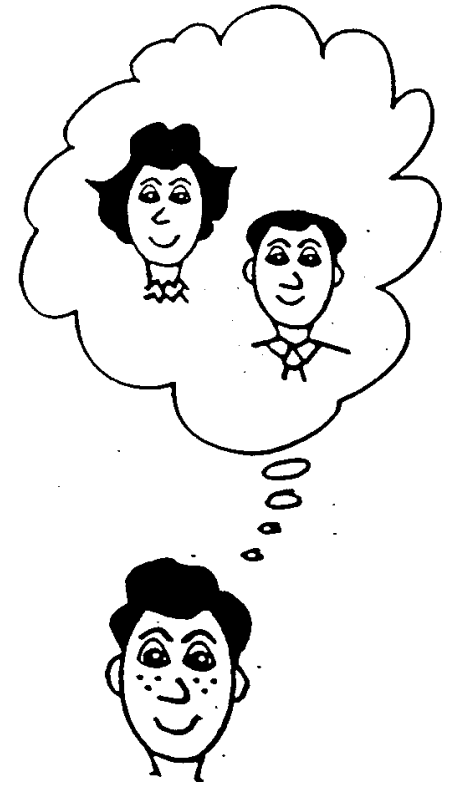

CONTIGUITY

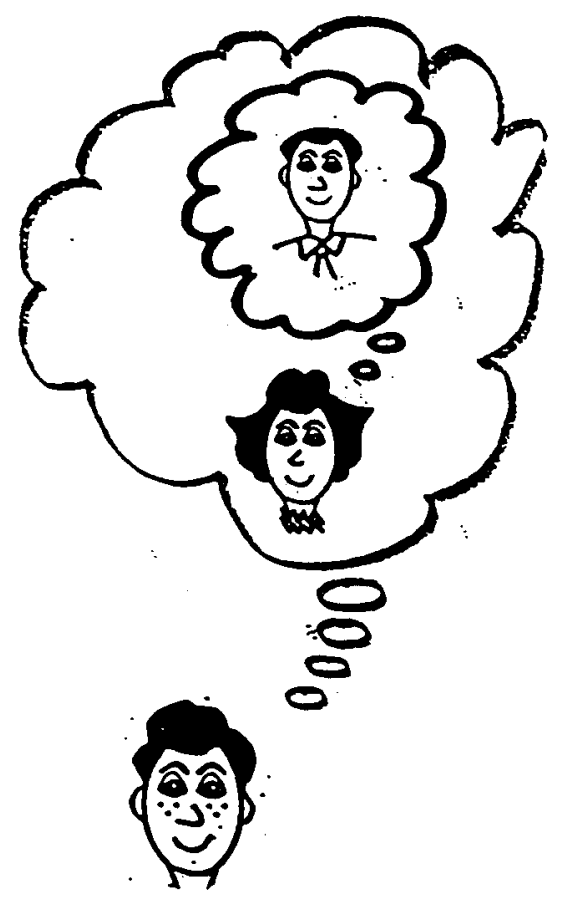

ONE-LOOP RECURSION

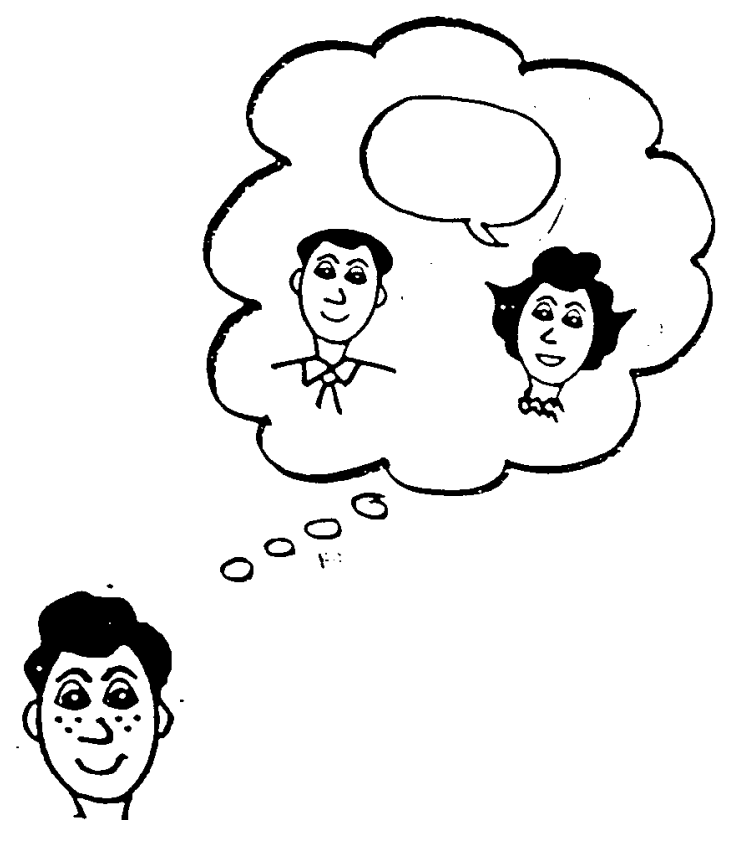

\section{ACTION}

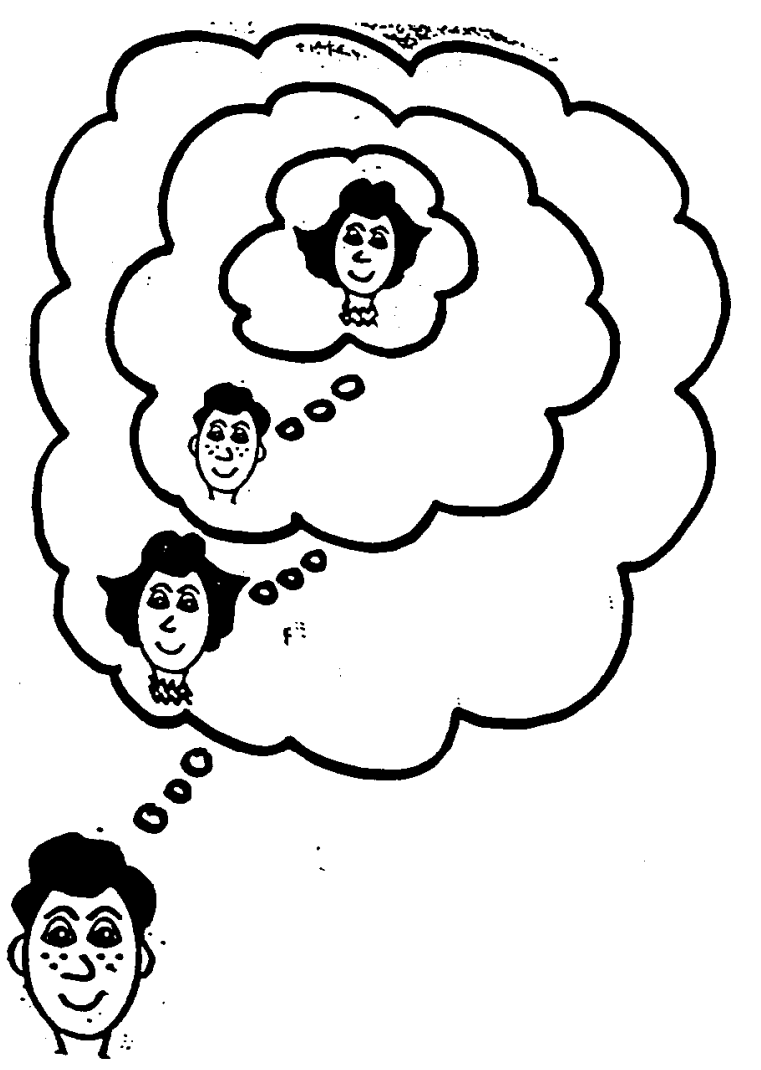

TWO-LOOP RECURSION 


\section{Vita}

\section{Dana Futoran}

\section{Department of Psychology}

West Virginia University

Morgantown, WV 26506-6040

Office Phone: 304-293-2001 Ext. 863

Home Phone: 724-437-5319

E-Mail Address: DFutoran@WVU.edu

FAX: 304-293-6606

\section{Educational History}

1998-present West Virginia University, Morgantown, West Virginia

Major: Community Counseling

Expected Degree: M.A., May, 2000

1997-present West Virginia University, Morgantown, West Virginia

Major: Developmental Psychology

Expected Degree: M.A., May, 1999

1993-1997 Duke University, Durham, North Carolina

Major: Psychology

Degree: B.S., Cum Laude, 1997

\section{Professional Positions}

1996-1997 Research Assistant, Duke University, Part-time position.

Duties: Assisted in research on longitudinal study in mother-child interaction, language acquisition, and memory in children at 24, 36, and 42 months. Design, subject recruitment, data collection, and transcription using CHILDES and SALT.

Supervisors: Carol Eckerman, Ph.D. and Sherry Didow, Ph.D.

\section{Teaching Experience}

1999-present Group Discussion Leader. Human Sexuality (Multidisciplinary Studies Undergraduate course, lecture course of 100 students with 8 weeks of discussion groups of 10 students each)

Duties: Lead one discussion group and maintain student records.

Supervisor: Nina Spadaro, Ed.D. 


\section{Teaching Experience continued}

1998-present Graduate Teaching Instructor. Introduction to Human Development (Psychology Undergraduate course, two sections of 60 students, multi-media presentations).

Duties: Give lectures, lead discussions, grade and maintain student records.

Supervisor: Anne Watson, Ph.D.

1997-1998 Graduate Teaching Assistant. Psychology as a Profession (Psychology Undergraduate course, 150 students each semester, multi-media presentations).

Duties: Give lectures, obtain guest lecturers, grade and maintain student records, and develop course materials.

Supervisor: Stanley Cohen, Ph.D.

\section{Membership in Professional Organizations}

American Counseling Association (Student Member)

American Psychological Association (Student Member)

Society for Research in Child Development (Student Member)

Southwestern Society for Research in Human Development (Student Member)

\section{Professional Activities}

1. West Virginia University Faculty Development Seminar, presented Psychology 19 course Web site, 1999.

2. Guest Lecturer for West Virginia University Graduate level course: Counseling Children, topic: Child Development as it pertains to counseling children, 1999.

3. Student representative to the Diversity Issues Committee, Department of Psychology, West Virginia University, 1998-present.

4. Student representative and secretary to the Undergraduate Training Committee, Department of Psychology, West Virginia University, 1997-1998.

5. Assistant Undergraduate Advisor, Department of Psychology, West Virginia University, 1997-1998. Duties include advising both pre-psychology majors and declared majors, as well as prospective students, maintaining department bulletin boards, subject recruitment for research studies, oversee directed study and teaching practicum undergraduate student courses, and assist with course evaluations. 


\section{Grants}

1. West Virginia University Eberly College of Arts and Sciences Travel Award, \$250, 1999. D. L. Futoran

2. West Virginia University Doctoral Student Travel Grant, \$200, 1999. D. L. Futoran.

3. West Virginia University Department of Psychology Alumni Fund Research and Travel Award, \$50, 1999. D. L. Futoran.

4. West Virginia University Instructional Technology Support Grant, \$2033, 1998-1999. S. H. Cohen and D. L. Futoran, Principal Investigators.

5. West Virginia University Eberly College of Arts and Sciences Summer Grant, \$1730, 1998-1999. S. H. Cohen and D. L. Futoran, Principal Investigators.

6. West Virginia University Doctoral Student Travel Grant, \$200, 1998. D. L. Futoran.

7. West Virginia University Department of Psychology Alumni Fund Research and Travel Award, \$140, 1997-1998. D. L. Futoran and J. Joersz, Principal Investigators.

\section{Presentations at Professional Meetings}

1. Theory of Mind and Attentional Processes in Elementary School Children. A. Wilson, \& D. L. Futoran, Society for Research in Child Development, Albuquerque, NM, 1999.

\section{Works Completed}

1. We have redesigned the introductory psychology class entitled Psychology as a

Profession at West Virginia University in order to incorporate the Internet and create a more interactive classroom environment. S. H. Cohen, \& D. L. Futoran

\section{Works in Progress}

1. Theory of Mind and Executive Functions in Elementary School Children. D. L. Futoran, A. C. Watson, \& A. W. Strange, manuscript in preparation.

2. Theory of Mind and Attentional Processes in Elementary School Children. A.W. Strange, A. C. Watson, \& D. L. Futoran, manuscript in preparation. 


\section{Volunteer Experience}

1. Co-counseling sessions with Nina Spadaro, Ed.D., Morgantown, WV, September, 1998 to present. Individual and Family Psychotherapy with clients of all ages, gender, and socioeconomic backgrounds.

2. School counseling at Mountainview Elementary School, Morgantown, WV, January, 1999 to present. Supervision under Head School Counselor, Michael Fike, M.A.

Individual and group counseling sessions which include biblio-, art, play, and impact therapies, as well as administration of intelligence tests.

\section{Professional References}

Available on request. 